an officer must be invalided and this is serious to a man near the time when he may receive command of his battalion. The result of inquiries as to specific trouble was negative. His condition was as bad as could be, the breathlessness was very great and attended by anginal attacks.

When tested by Hill and Barnard's sphygmometer the maximum swing of the needle was at $200 \mathrm{Hg}$, the effects of back pressure being seen in the oedema of the legs and the size of the liver. The heart was failing, and the constant pain and the breathlessness were very trying. I gave morphine sulph., guarded by a dose of atrop. sulph., to check the restlessness, and regular doses of nitro-glycerine to lessen the resistance ahead, and so let the blood get away; hypodernjics of strychnine to brace the heart muscle, an occasional blue pill and seidlitz. By the time Sir WVilliam Broadbent saw him the dose of morphine was gr. $\frac{1}{8}$ a day.

The condition of his heart is described in the note following, written for me by Sir William Broadbent, who saw him on October 21st, a month after his arrival in Windsor :

Sir IVilliam writes: "While tranquil there was no respiratory distress, but the breath was short on very slight excrtion. There was considerable oedema of the legs. The pulse was large, sudden, short, and collapsing, indicative of extreme aortic incompetence; when the hand was raised the beats scarcely reached the wrist; the carotid throb was ver'y conspicuous. The abdomen was tumid and the liver large. The apex beat was diffuse, and could be ielt in the sixth space, and could be felt as far out as the anterior axillary line ; the cardiac impulse generally weak. The area of dullness was very extensive. Dullness was present from the right of the sternum from the sccond space down wards; the upper limit followed the third space, and curved downwards outside the nipple. $\Lambda$ t and to the left of the nipple a systolic cnlu'mul' was heard, and over the heart generally a loud diastolic murmur, evidently" iortic. In the right second space there was also a systolic murmur audible along the aorta and in the carotids. No aortic sceond sound could te heard in the neck or in the aortic area. My prognosis was extremely grave, and it did not secm to me possible that life cousd be prolongcd till the end of the year."

The accumulation of fluid in the abdomen was so great that on October 28th I was obliged to tap him. This I did by Southey's tube, and drew off over 7 pints, when the fluid would not run freely and he was feeling the restraint of one position so much I had to remove the needle. The shock of tapping was very great, so that I felt it advisable to drain off the fluid which was, as it were, on the wrong side of the circulation, by needles in the legs.

The dose of nitro-glycerine was gradually increased till he had tivo tablets of $\frac{1}{20}$ gr. each every hour, and at times an extra tablet. The dose of morphine was increased till he had as much as $I^{1}$ gr. in the twenty-four hours. The pain in the aodta was kept at bay, and he was able to take an interest in life and would not realize that his condition could be really serious. In December he had a very bad time for about a week ; it did not seem possible that he could rally, and he was only kept going with inhalations of oxygen ten minutes to every hour, strychnine frequently, and brandy at times for several days.

He was drained through the legs by having two needles in each leg, and each time these needles were put in they drained over 8 pints. At the middle of December the fluid had increased so much in the abdomen, in spite of the draining through the legs, that I felt bound to take the risk of tapping the abdomen again. He was given a dose of morphine half an hour before, and a dose of brandy immediately before I inserted the needle, and I gave a hypodermic injection of strychnine as soon as I had withdrawn the trocar. In spite of all this the patient almost died from shock and I had to rest content from that on witl: draining the legs.

From the start he.was kept free of digestive trouble by the simple plan of separating his proteid from his carbohydrate meals. The blood pressure was steadily lowered to meet the failing heart, and at a fortnight before the end the maximum swing was at 100 , and the small amount of $120 \mathrm{~mm}$. Hg. pres sure compressed the pulse.

The condition of the legs was one calling for anxious care. and though they were tapped over twenty-five times, and four needles used at each tapping, so well did his nurses care for the legs that they never became inflamed from the needles. The legs were washed twice in the twenty-four hours with a solution of perchloride, dried with new cotton wool. and dusted with a dusting powder containing some calomel, etc. When they showed signs of acute inflammation towards the end from the continual congestion they were dressed with thermiluge on lint.

The reason for increasing the morvhine sn much was that when he camr quite from under its soothing influence he was very anxious to stand up as the breathlessness came on so badly, and I knew that standing in his state meant collapse and death.

When he had been taking the chocolate tablets of nitroglycerine for some weeks they had a tendency to make him sick, so I gave nitrite of soda as a change. By the aid of the nitrites it was possible to lower the work so much that instead of dying suddenly from the usual cause in aortic disease-failure of vis-a-tergo in the arteries, he died of the combined effect of venous stasis and failure of vis-a-tergo in the arteries. Gangrene set in in both legs on February 2oth, and he had a great deal of fever as a result, the temperature going to $104^{\circ}$ and his pulse to 130 . He was conscious up to two hours before the end, and died quite easily, 36 hours from the onset of the gangrene, without the legs becoming septic.

For months his breathing during sleep was of the CheyneStokes variety. The pulse was irregular, and at times intermittent, and there was a general dilatation of the arch of the aorta. The amount of albumen in the urine never increased beyond one-eighth. The lungs were remarkably free of congestion, and at times he suffered from slight pleurisy.

The case may be put briefly as follows:

An acute aortitis caused puckering of the orifice and a regurgitant murmur, the heart for a couple of years compensated by enlargement of the left ventricle, under the strain of service in India the compensation failed somewhat rapidly, and dilatation set in ; this caused leakage at the mitral orifice and the usual back pressure began to tell.

According to the textbooks and most observers the advent of a mitral lesion in aortic disease is looked on as a sign that the end is near at hand, especially when albumen is present in the urine, yet in this case he lived on in a state of comparative comfort for over six months, and during the last five months he had not more than three attacks of angina.

The amount of morphine that was given without a single untoward symptom was I think worthy of note; towards the end it was possible to reduce the morphine to $\frac{1}{2}$ gr. a day for days at a time. He was unable to sleep, except in a sitting position.

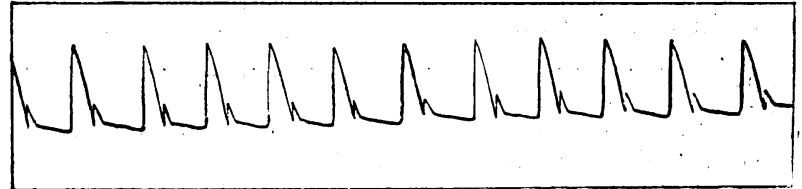

The pulse tracing was taken early in October, and shows a sudden fall to almost the base line.

\section{CASE OF ACROMEgALY.}

BY W. B. HUNTER, M.D. Londonderry.

Srice but few cases of this disease appear to have been reported as occurring in Ireland, notes of the following case may be of interest :

IIistory-Early in April. Igo3, the patient presented herself at the Londonderry Eve. Ear, and Throat Hospital, complaining of defective sight. She was found to be suffering from old iritis in both eyes, and, though I observed at her first visit the unpleasing condition of her face the thought of the true nature of that did not occur to me until I observed her hands at a subsequent visit when she had no gloves on. Having examined the hands, it was easy to see the nature of the case, and then, of course, the old iritis lost much of its interest and consideration. Of the two plotographs of the patient, one was taken before the disease was supposed to have started, and the other quite recently. The case is thought to date from twelve or fourteen years ago. On looking back, the patient and her friends think they noticed some change about that time in the facial expression, and that the usual sizes of her gloves and boots were found in some way to be too tight gloves and boots were found in some way to be too tight ference also to other collateral events and associations. The patient can ascribe no cause for what has so slowly eveutuated in her present condition-no fright, or mental or bodily strain, no emotional disturbance or accident. Her family history gives no clue unless that there be some connexion between her disease, and her father dying suddenly from heart disease and her mother of "dropsy." The patient, has never been married, and is now in her $65^{\text {th }}$ year. She says menstruation stopped before she was 50 , but that three years after this event slye was affected with a sudden and copiou recurrence, almost like "a flooding." which lasted three days, and since theu there has never been any return. Whether there is any connexion between this condition and the commencement of the disshe complains that her gencral health at present is very poor and 
frail, that she is very easily upset and exhausted on any exertion; that though she has always had, and has still, a good appetite, she suffer's much from " waterbrash," that is, acidity and stomach disturbance. It may be noted that, when asked, she denies ever having had atticks of vomiting, though sometimes she has a tendency that way. She says also that at first, and for a good many years, she suffered much from headaches, but recently these have stopped. Much complaint is made, too, of pains in her ankles and all the small joints of her feet, a burning kind of pain in one small spot in the right thigh, though there is no cliscoloration, and of a pain in her other leg which she calls sciatica. ()ther complaints are much sweating, distressing dryness of the mouth with thirst, some tinnitus and palpitation, besides, of course, the bad sight with pain in the eyes.

State on Examination.- - On examining her heart a murmur can be lieard at both base and apex, and there is much irregularity in its action, some beats being very feeble, so that at the wrist they are not felt at all. The extremities are often cold and clammy, and the nails blue. There is much vasomotor disturbance, the face changing in colour very frequently. During a short examination or conversation this can be observed. The usual pallid or dirty-white colour changes

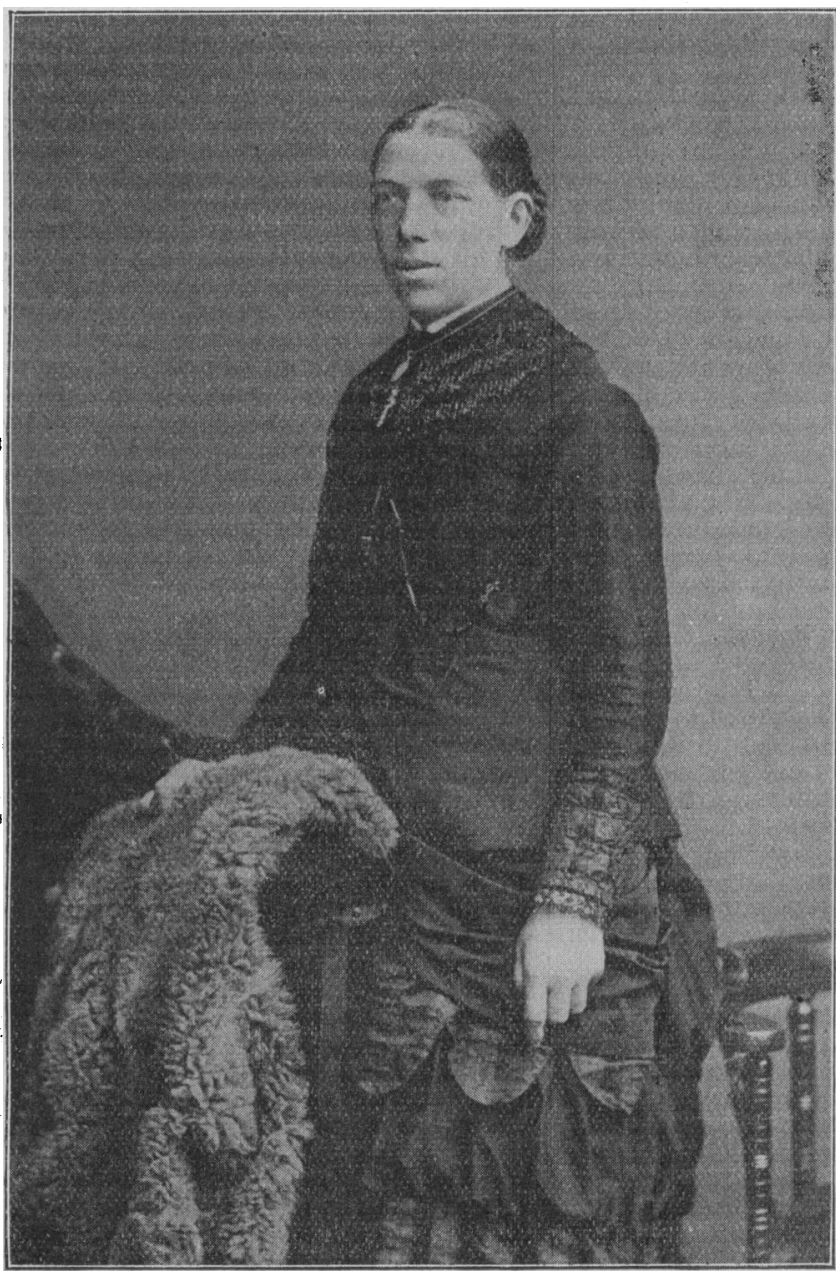

Early photograph.

visibly, though slowly, into a dark-red or purple colour, with some heat and sweating, then soon returns again to original state. The slightest emotion does this, and sometimes any bodily exertion. When this occurs she feels more exhausted. About her respiratory system there is nothing in particular to notice. With regard to her sight, her eyes are prominent, eyelids oedematous, with smarting and pain, which latter may be due to the iritis. The whole uveal tract or region in the left eye has suffered so much from chronic inflammatory action that no knowledge of the fundus can be got. In the right eye things are not so bad. The pupil can be irregularly dilated with atropine, and a sight of the disc got, and some of the periphery of the fundus. The dise looks healthy, unless, perhaps, for a too congested condition and some blurving. These might be the beginning of a neuritis. She can still see to read with this eye with plus glasses and to do some'needlework. On using the perimeter there did not seem to be any contraction of the field of vision; there was no temporal hemianopsia. Although the eyes are prominent there is neither Graefe's nor Stellwag's signs, the lids can easily cover the globes and there is no oculo-motor paralysis, The urine showed no indications of either sugar or albumen.
On looking at the recently-taken photograph and comparing it with the earlier, it will be seen that there is much enlargement of the nose, lips, upper and lower jaws, with projection of jaws so as to give the face a somewhat oval form. The tongue, which is not seen, is very large, flat, and broad, and fills the whole mouth. The teeth in the lower jaw are long and loose and covered with a dirty, thick, grey coating of sordes. Those of the upper jaw are very defective, and when the mouth is closed are overlipped by those of the lower jaw. The manubrium is broadened out and there is considerable enlargement of the bones at the sterno-clavicular joints. The clavicle itself is enlarged as well as the sternal ends of the ribs, which appear as large knobs. The hands are broadened and the several joints are large and flattened out; the ends of the fingers are much flattened and' square; the palms are thick and have a cushiony feel when pressed. The lower ends of the fibulae are greatly enlarged and the ankle-joints massive; all the smaller joints are

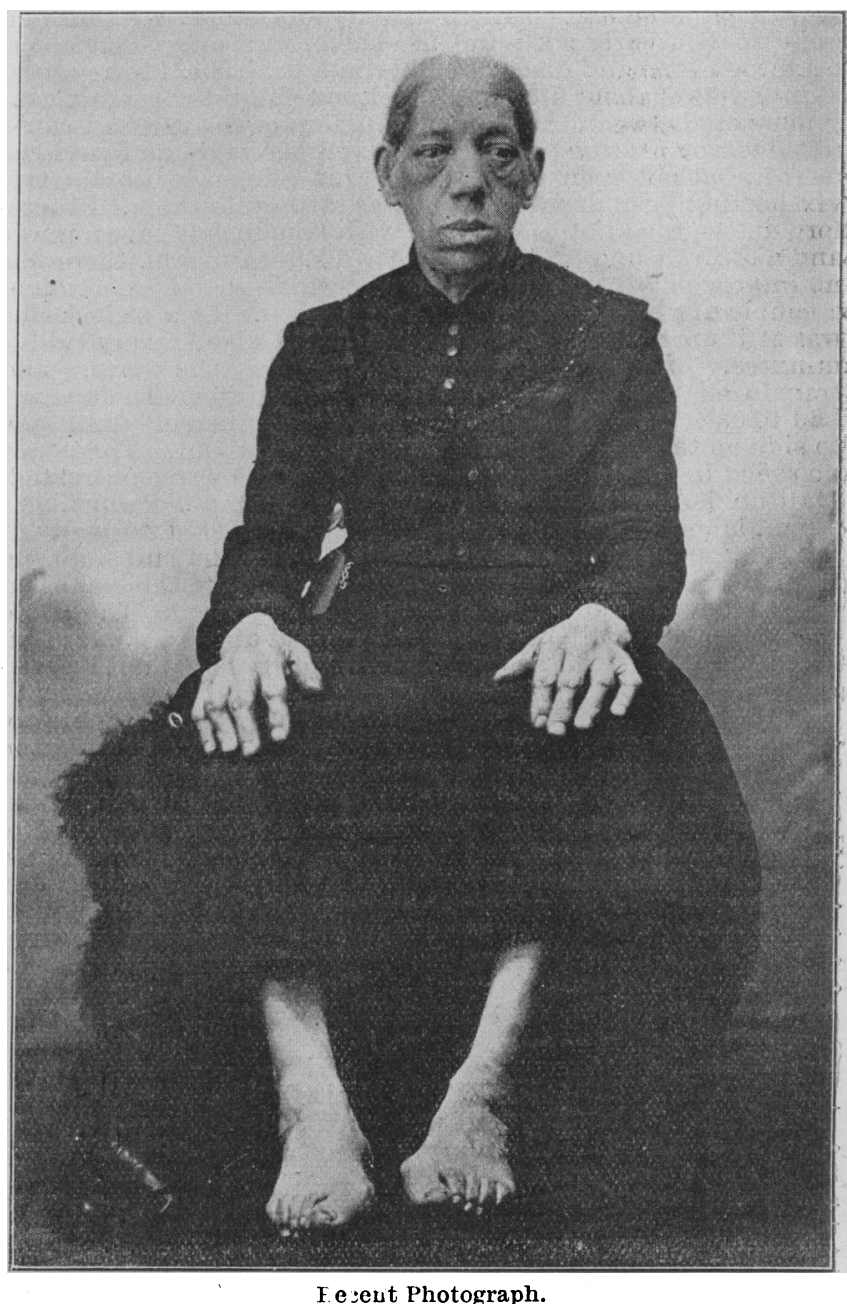

thickened and big. The soles look puffed up, being raised hy a thickened development, which feels when pressed by fingers like a soft dough covered by a velvety envelope.

The woman being an out-patient, no closer examination of the body was made, but she says there are some small growths on different parts of the skin of the trunk, that there is no extra growth of hair on the pubes nor any enlargement there. and that there are no mammary glands now. Her mental condition is good, and she is not uncheerful, sometimes joking about her peculiar conditions.

The most observable subjective symptom, I think, is the great vasomotor disturbance. As regards life, I think the prognosis is bad, chiefly on account of the state of her heart.

Beouests. - The late Mr. R. G. Trimmer has left the sum of $£ 3,00$, free of duty, to the Trimmer's Cottage Hospital, which was founded by his father, the late Mr. George Trimmer. 